\title{
Addressing Alternative Conceptions about Transition Metals among Form Six Students using Information and Communication Technology based Instruction
}

\author{
Mageswary Karpudewan ${ }^{1 *}$, Nilavathi Balasundram ${ }^{1}$ \\ ${ }^{1}$ School of Educational Studies, Universiti Sains Malaysia, MALAYSIA
}

Received 30 November 2018 - Revised 16 January 2019 • Accepted 24 January 2019

\begin{abstract}
This study was conducted to reduce the incidence of alternative conceptions about transition metals among form six students. A quasi-experimental design was carried out involving 79 students from two intact classes that were randomly classified as the treatment $(\mathrm{N}=47)$ and the comparison $(\mathrm{N}=32)$ groups. Information and communication technology-based instruction (ICT) was used in this study with the treatment group while a traditional teaching method was used with the comparison group. For the quantitative study, nine two-tier items were administered in a conceptual test after instruction to the 79 form six students in both the groups to ascertain their understanding about transition metals. Five students from the treatment group were selected for interviews before and after the instruction to obtain further insights into their understanding. An independent samples t-test analysis was used to compare the total scores of the two groups in the transition metals conceptual test. The outcome revealed that there were statistically significant differences in the test mean scores between the comparison and treatment groups (Mtre $=8.47$; SDtre $=0.69$; Mcomp = $3.91 ; \mathrm{SDcomp}=0.96 ; \mathrm{t}=23.103, p<0.001$ ). The results from the analysis indicated that students from the treatment group showed significantly greater levels of achievement than the students from the comparison group. Furthermore, the percentage of alternative conceptions among students in the treatment group was lower than those of the comparison group students.
\end{abstract}

Keywords: alternative conceptions, form six students, ICT-based instruction, transition metals

\section{INTRODUCTION}

Almost all science topics including the study of transition metals involve the incidence of alternative conceptions among students. The study of transition metals is covered in inorganic chemistry in Form 6 (18 to 19 years old) in the Malaysian education system. This study focuses on alternative conceptions held by students about transition metals. ICT-based education is about incorporating technology across the curriculum by transferring knowledge, facts and information using ICT tools such as computers, lap tops, projectors, hand-held devices and more (Anderson, 2008). It was envisaged that the alternative conceptions about transition metals that are held by students could be reduced using ICT-based instruction.

Transition metals were first introduced to students in the Periodic Table topic in the first school term. Students would then learn about transition metals in detail in inorganic chemistry, in the second term. The transition metals topic in Form 6 covers physical properties and chemical properties of the first row of transition metals such as their nomenclature, the formation of different colours in transition metal compounds, the ability to form different oxidation states, formation and bonding of complex ions, transition metals as good catalysts and their uses.

(C) 2019 by the authors; licensee Modestum Ltd., UK. This article is an open access article distributed under the terms and conditions of the Creative Commons Attribution License (http://creativecommons.org/licenses/by/4.0/). \kmageswary@usm.my (*Correspondence) $\square$ bnilavathi@gmail.com 


\section{Contribution of this paper to the literature}

- To this end literature on science education have documented about students developing alternative conceptions during the science lessons. However, very few studies reported on alternative conceptions about transition metals.

- The paper illustrates on using ICT based instruction in addressing alternative conceptions on transition metals. Many studies have employed different approaches in addressing alternative conceptions. This study specifically illustrates on using ICT in learning about transition metal.

- The ICT based instruction introduced in this study serves as a guide and exemplary for teachers to adapt the method in teaching about transition metal.

\section{THEORETICAL BACKGROUND}

The main objective of science education is to teach science concepts meaningfully to make students aware of how to use these concepts in their daily lives. Ausubel (1968) argued that meaningful learning would occur if new concepts are compatible with the old concepts. It is important to know what prior knowledge students bring to the classroom in order to help them build new concepts (Tsai, 2000).

Chemical knowledge seems to be difficult because it is learned at three levels which are "sub-microscopic," "macroscopic" and "symbolic" (Johnstone, 1991). The macroscopic level is something that is physical and visible, for example, students are able to see the colours of the transition metal compounds. Formation of variable oxidation states in terms of energies of the $3 \mathrm{~d}$ and $4 \mathrm{~s}$ orbitals are at the sub-microscopic level which refers to what is molecular and invisible. The symbolic level involves equations and chemical symbols such as formation of complex ions with different types of ligands. Alternative conceptions exist because of the difficulty in comprehending a topic. Thus, alternative conceptions will indirectly hinder the acquisition of the new knowledge. This is similar to the suggestion by Özmen (2004) who agrees that alternative conceptions will delay students' learning of subsequent concepts. In addition, if students' preconceptions do not match with scientifically acceptable concepts, they may lack the necessary basic ideas to build further knowledge that is needed to understand more advanced concepts (Mulford \& Robinson, 2002).

Science education research has shown that children as well as adolescents have their own ideas and concepts about their surroundings and environments. For instance, Nieswandt (2001) stated that children develop their own ideas about nature and everyday life at a very early stage. According to Kao (2007) the sources of the students' alternative conceptions are diverse and are derived from their school teachers, experiments, textbooks, life experiences, and the use of anthropomorphism, analogies, and intuition. Alternative conceptions reflect situations in which students provide mistaken explanations to events about their daily experiences.

Several studies have been conducted to investigate the alternative conceptions that students hold in various science topics. These topics include:

(1) Chemical bonding (Coll \& Treagust, 2003; Taber \& Coll, 2002), heat, temperature and energetics of chemical reactions (Goedhart \& Kaper, 2002);

(2) Conservation of matter, balancing of equations and stoichiometry (Agung \& Schwartz, 2007); (3) acid strength in organic chemistry (McClary \& Bretz, 2012);

(4) Chemical thermodynamics (Hadfield \& Wieman, 2010; Sözbilir, Pinarbasi, \& Canpolat, 2010);

(5) Solutions, solubility of salts and the particulate nature of salts in solutions (Smith \& Nakhleh, 2011);

(6) Acid-base chemistry (Artdej et al., 2010; Drechsle and Schmidt, 2005; Furió-Más, Calatayud, \& Bárcenas, 2007).

(7) Transition metals (Sreenivasulu \& Subramaniam, 2014)

However, studies rarely have investigated high school students' understandings about transition metals.

The incidence of alternative conceptions can be reduced using ICT-based instruction to enable students to relate theory with practice easily. Hu, Gong, Lai \& Leung (2018) supported that ICT benefits students learning science in wide range of topics. Teachers usually use technology-based instruments to reduce alternative conceptions about transition metals. Using ICT-based instruction will give students a better picture of the concepts compared to traditional methods of teaching. In fact, teaching and learning assisted with ICT has been increasing worldwide with its greater accessibility (Baytakar, 2000). Yushau, Mji and Wessels (2003) reported that visual representations on a computer screen are more beneficial to the students' understanding as compared to diagrams in books.

A study conducted by Sreenivasulu and Subramaniam (2014) revealed that transition metals is one of the topics from chemistry that is difficult to comprehend among the students. This is because of the abstract concepts that 
Table 1. Major propositional content knowledge statements defining instruction on transition metals

Item

No.

1. A transition metal in zero oxidation state is able to attract ligands and form metal complexes, e.g., Ni in oxidation state

1. zero forms nickel $(0)$ tetracarbonyl, $\mathrm{Ni}(\mathrm{CO})_{4}$.

2. The tendency for transition metals to involve all $3 d$ electrons in bonding will decrease once the $d^{5}$ configuration is

2. exceeded because the electrons will pair up and will not be available for bonding.

3. $\mathrm{Cu}^{+}$has unpaired $\mathrm{d}$ electrons which cannot take part in $\mathrm{d}$ - $\mathrm{d}$ transitions because the electronic configuration of $\mathrm{Cu}^{+}$is [Ar]

3. $3 d^{10} 4 s^{0}$, so it has completely filled $3 d$ orbitals.

4. $\mathrm{Cu}$ and $\mathrm{K}$ do not have the same ionisation energy for the loss of their 4s electrons because they do not have the same

screening effect of their inner electrons.

5. The reactivity of transition metals decreases from left to right across a period because the $\mathrm{d}$ orbitals are progressively

5. filled up with electrons.

6 The ionisation energy of transition metals down a group in the Periodic Table is not similar to that of the alkali metals

because the screening effect of the inner electrons of transition metals increases.

7. Transition metal ions are the only ones that are coloured as ions of non-transition metals like sodium, calcium, sulfide

chloride, iodide and bromide ions are colourless.

8. Transition metals can be good reducing agents because they have relatively low standard electrode potentials, e.g. $\mathrm{E}^{\circ}$ of

8. $\mathrm{Sc}^{3+} / \mathrm{Sc}=-2.08$.

9. Transition metals are good catalysts because they have empty or partially filled d-orbitals that can be used to form

9. temporary bonds with reactant molecules.

exist in chemistry especially about transition metals such as metallic bonding, $\mathrm{d}-\mathrm{d}$ transitions of electrons which emit colours, formation of complex ions, ligands and so on. Deficiency in understanding the chemistry of transition metals results in students developing alternative conceptions about the topic. A study by Sreenivasulu and Subramaniam (2014) identified several alternative conceptions about transition metals. These included: transition metals with zero oxidation state cannot attract ligands to form complex ions, $\mathrm{Cu}^{+}$has unpaired d-electrons which can take part in $\mathrm{d}-\mathrm{d}$ transitions, $\mathrm{Cu}$ and $\mathrm{K}$ have the same ionisation energy for the loss of their $4 \mathrm{~s}$ electrons due to similar screening effects, etc. Furthermore, Johnstone (1971) found that students have difficulty in conceptualizing how the splitting of d-orbitals occurs in transition metals. He also reported that knowledge of d-orbitals is the basic knowledge that a student should acquire in order to learn about splitting of d-orbitals.

\section{ICT-based Instruction}

In recent years, the use of ICT has been widespread because the use of computers and other electronic forms of media in science teaching saves time and helps students better understand science concepts (Lai, Hwang \& Tu, 2018). Most teachers and experts recognize the need for a teaching method using ICT facilities. Adam and Tatnall (2010) believe that ICT has positive impact on students' understanding of science concepts while Barak (2017) has suggested that ICT-based instruction plays a crucial role in current teaching and learning of science concepts. Computers are used as an additional tool in schools to achieve educational goals (Bayraktar, 2000). Education in the $21^{\text {st }}$ century that involves the use of ICT in the classroom plays a vital role in enhancing the teaching and learning process. The role of ICT is to help students in particular, to learn and teachers to perform their teaching more effectively (Goktas \& Yildrim, 2003). Integrating computers into the teaching and learning of inorganic chemistry can go a long way in solving the above problem, as it is an alternative approach that is available to teachers and students in the teaching and learning of chemistry (Anderson, 2002; Gyöngyösi, 2005).

The major propositional content knowledge statements covered in transition element instruction using ICT are shown in Table 1.

\section{PURPOSE OF THE STUDY}

This study was conducted with the purpose of reducing the incidence of alternative conceptions about transition metals among Form 6 students. The study was guided by the main research question (RQ): What is the effect of ICT-based instruction on reducing the incidence of alternative conceptions about the chemistry of transition metals among Form 6 students? 


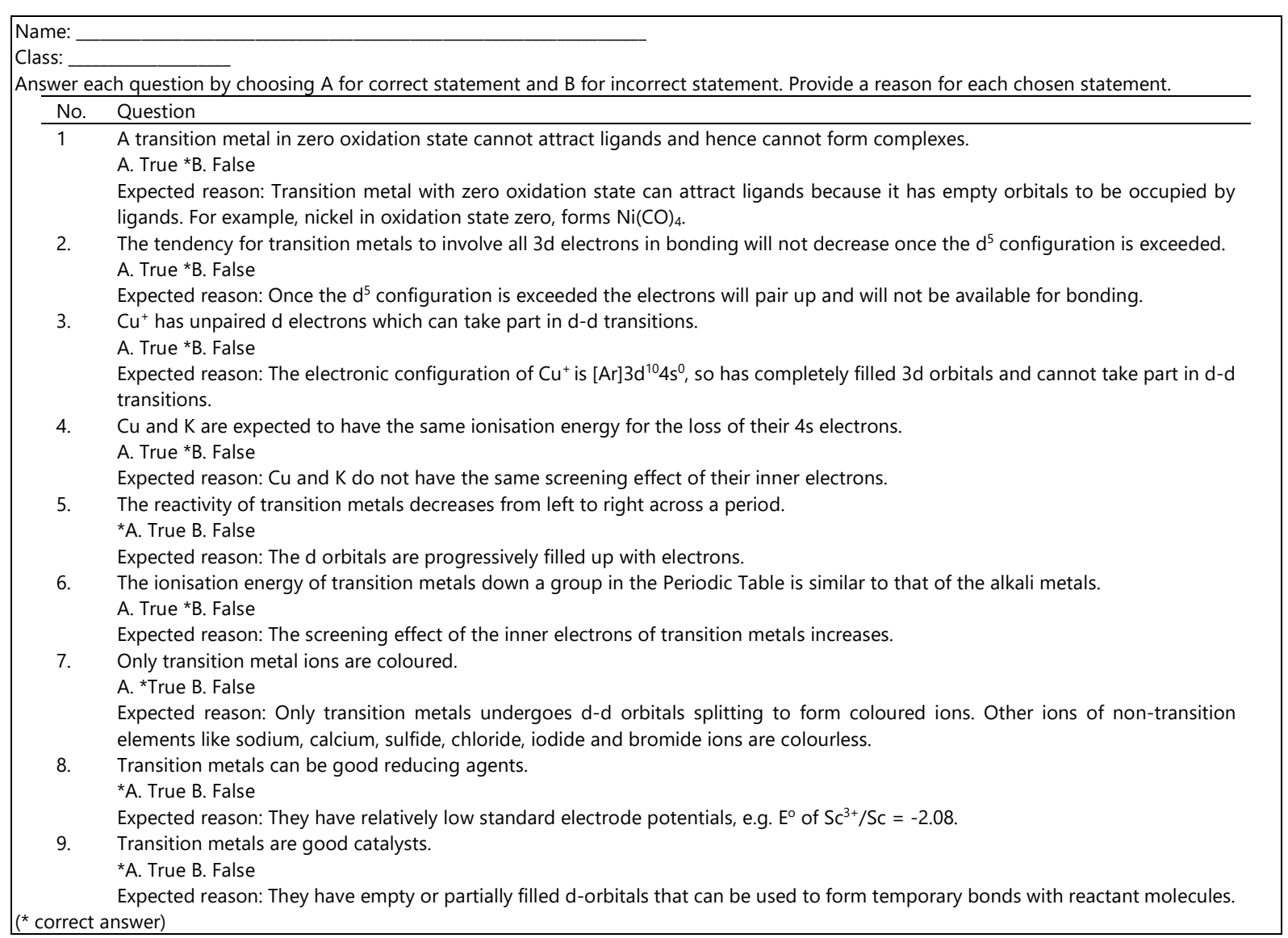

Figure 1. Questions included in the conceptual test

\section{METHODS}

\section{Sampling and Research Design}

This study was aimed at reducing the alternative conceptions about transition metals among form six secondary school students. For this purpose, a quasi-experimental design, involving 79 form six (18 to 19 years old) science stream students was used in this study. The students were divided into two groups where one class of 32 students (referred to as the comparison group) was taught using a traditional method. The other group of 47 students from two classes (referred to as the treatment group) was taught using ICT-based instruction. Form Six is pre-university level studies. After completing Form Six students will be enrolled into degree courses of their choice. Chemistry is a requirement for students to enroll into science, technology, engineering and mathematics courses at tertiary level.

\section{Research Instrument}

Both quantitative and qualitative research methods were used in this study. A conceptual test was administered to both groups after the treatment. As the students were introduced to the chemistry of transition metals for the first time, it was not considered necessary to administer a pretest. In this test, true-false questions were administered to students to identify alternative conceptions that were held by them. This conceptual test that was adapted from a study by Sreenivasulu and Subramaniam (2014), consisted nine multiple-choice true-false questions. Each item was followed by an open-ended question that required students to give a reason for the answer chosen in the item. Items in the conceptual test are listed in Figure 1 together with the expected reasons In addition, an interview session was conducted with the Form 6 students from the treatment group, before and after instruction, to further enhance the results of this study. 

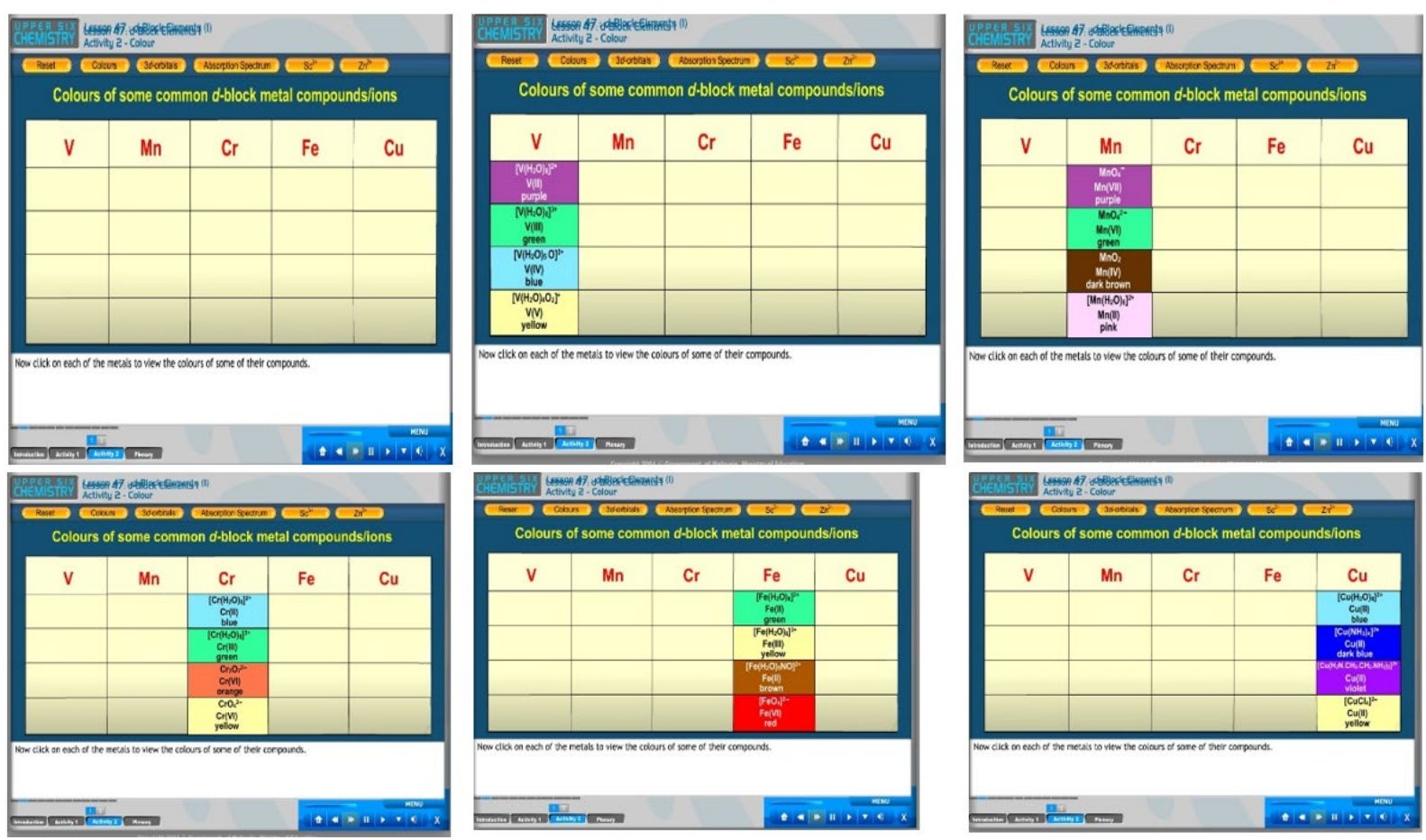

Figure 2. Shows a series of screen shots that the teacher could use to show that the colours are due to $d$ electron transitions

\section{Treatment}

Nine periods a week were allocated for chemistry lessons and three periods were allocated for laboratory sessions together with the students' project work. Each period consisted of forty minutes of lesson time.

\section{Traditional Teaching Method}

The traditional teacher-centered method was used to teach transition metals to the comparison group. A white board, textbooks and additional notes were used in the classroom by the teacher. This instruction was more chalkand-talk in nature where the students listened passively to the teacher and took down notes when necessary. This was followed by discussion of examples and a few exercises from the textbook. The teacher administered the conceptual test to identify the alternative conceptions at the end of the instruction.

\section{ICT-based Instruction}

ICT-based instruction was used with the treatment group. The teacher used the teaching courseware on a CD provided by the Ministry of Education. This courseware comprised of lessons in each topic as well as practical activities and problems that the students had to solve. During the lessons the students were shown the formation of complex ions, d-d transitions, etc. using the CD. This was followed by a group activity after each lesson. For example, after students had viewed the video of the formation of complex ions, they were required to form their own complex ion using a different central metal ion and ligands. A representative from each group then explained their complex ion to the class. The teacher then gave her opinions and comments on the students' presentation.

Figure 2 shows several screen shots from the CD that the teacher could use to show the colours of the ions of various transition metal ions. 

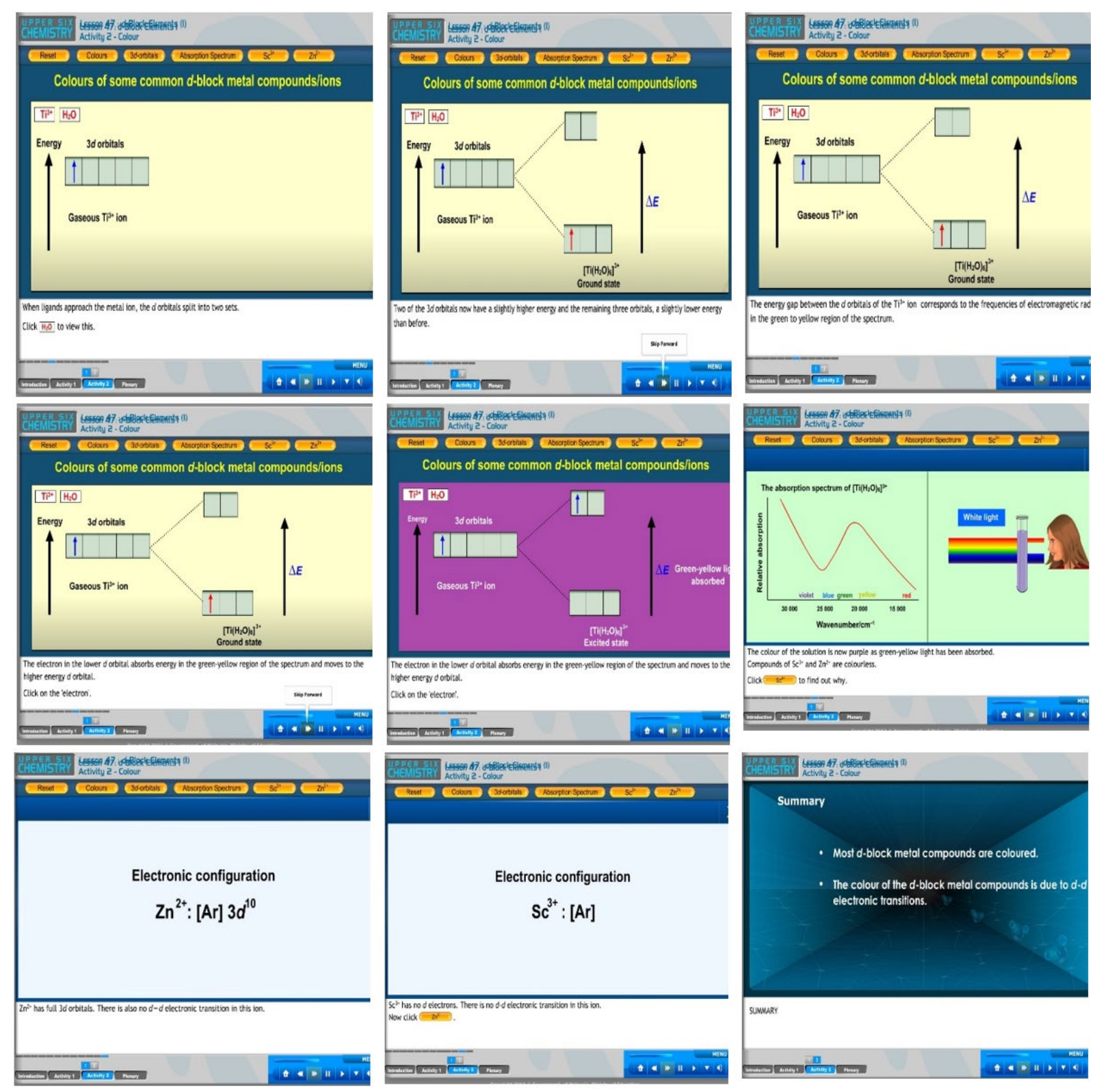

Figure 3. Colours of ions due to d electron transitions

To further enhance their knowledge about the formation of complex ions, the students carried out laboratory work. It helped students to have a clearer picture about the concepts and enhanced their understanding about the transition metals topic. Students were shown examples of complex ion solutions (e.g., $\mathrm{Ni}\left(\mathrm{NH}_{3}\right)_{6}{ }^{2+}$ and Cu(NH$)_{4}{ }^{2-}$ ) to emphasize the various colours of the solutions (see Figure 4). 


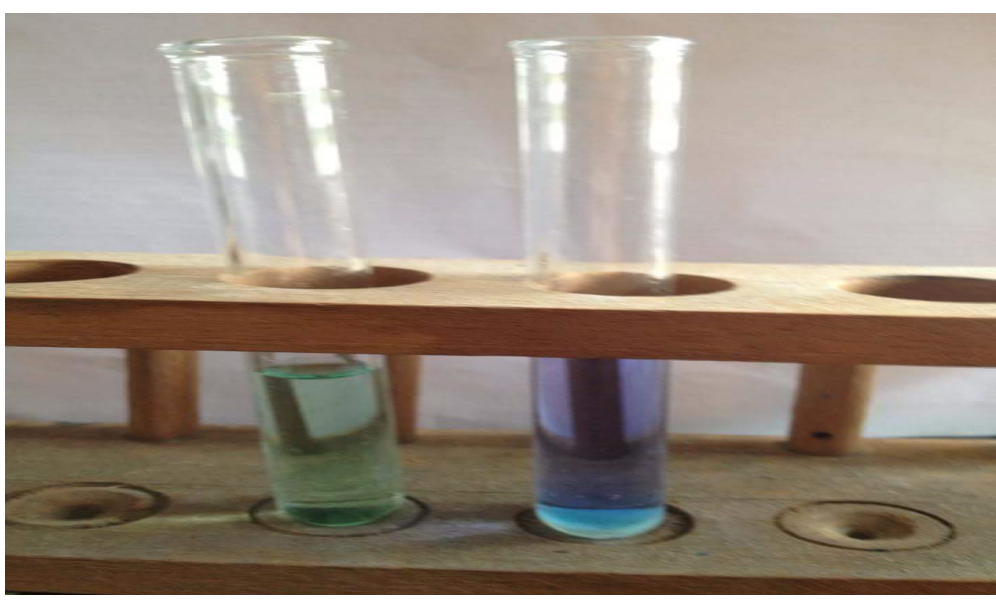

Figure 4. Examples of coloured complex ion solutions

Table 2. Themes formed after the reviewing and refining process

\begin{tabular}{|c|c|}
\hline No. Initial theme & Theme \\
\hline 1. The oxidation number of transition metals ions & \multirow{2}{*}{$\begin{array}{l}\text { Nature of transition metal ions to form } \\
\text { complex ions }\end{array}$} \\
\hline Bonding in the complex ion & \\
\hline Comparison of ionization energy between copper and potassium & \multirow[b]{2}{*}{$\begin{array}{l}\text { Comparison of ionization energy between } \\
\text { alkali metals and transition metals }\end{array}$} \\
\hline $\begin{array}{l}\text { Comparison of the trend in ionization energy between alkali metals and } \\
\text { transition metals }\end{array}$ & \\
\hline Comparisons of color between transition metal ion and other ions & \multirow{2}{*}{ Colors in transition metal ions } \\
\hline The explanation for some transition metal ions which are not colored & \\
\hline Reactivity trend of transition metals across the period & \multirow{2}{*}{ Chemical reactions of transition metals } \\
\hline 8. The strength of transition metals as reducing agents & \\
\hline
\end{tabular}

The teacher gave students exercises after each sub-topic to do as homework.

\section{Data Collecting Method}

An item was considered correct when only both parts of items were correctly answered (Treagust, 1988). No marks were awarded for any other combination of answers. Interviews were conducted with five students from the treatment group who were randomly selected by the first author, to ascertain the extent of their alternative conceptions before and after instruction. There was no time limit for the interview sessions.

\section{Data Analysis}

For the quantitative results, the posttest data of the comparison and treatment groups were analyzed using SPSS 21.0 (Statistical Package for the Social Sciences). For the qualitative results, five interview questions were used in interviews to ascertain the treatment group students' understandings about transition metals before and after instruction.

\section{RESULTS}

The results of quantitative and qualitative analysis of the data are reported below.

\section{Comparison of the Total Scores in Transition Metals Posttest}

The transition metals conceptual test was administered to the students from the comparison group and treatment group after the treatment had been carried out. Independent samples t-test analysis showed statistically significant differences in the test mean scores between the comparison and treatment groups (see Table 2). These results show that the students in the treatment group exhibited improved understanding about transition metals compared to the students from the comparison group. 
Table 3. Means and standard deviations for the results of the posttest

\begin{tabular}{|c|c|c|c|c|c|c|}
\hline \multirow{2}{*}{ Test } & \multicolumn{2}{|c|}{ Treatment group $(\mathrm{N}=47)$} & \multicolumn{2}{|c|}{ Comparison group $(\mathrm{N}=32)$} & \multirow{2}{*}{$\mathbf{t}$} & \multirow{2}{*}{$p$} \\
\hline & Mean & SD & Mean & SD & & \\
\hline Post-test & 8.47 & 0.69 & 3.91 & 0.96 & 23.103 & $<0.001$ \\
\hline
\end{tabular}

\section{Students' Alternative Conceptions about Transition Metals}

The objective of this study was to reduce the alternative conceptions about transition metals among Form 6 students using ICT-based instruction. The two-tier questions in the conceptual test evaluated students' understanding in four areas which are formation of complex ions, variable oxidation states in transition metals, ionisation energy of transition metals, formation of colours in transition metal ions and uses of transition metals. The alternative conceptions that were identified are shown in Table 3.

As shown in Table 3, several alternative conceptions were identified about transition metals through the responses given by the students using the two-tier questions. There is a large difference in the percentage of the alternative conceptions between the comparison group and the treatment group students. The percentage of alternative conceptions held by the comparison group students ranged from $44 \%$ to $72 \%$, while for the treatment group students the percentage of alternative conceptions ranged from $2 \%$ to $11 \%$. This clearly shows that ICT-based instruction had resulted in a significantly lower incidence of alternative conceptions among the treatment group students compared to the traditional instruction with the comparison group. For qualitative data, the same five interview questions were used before and after instruction to determine the understanding about transition metals of the treatment group students. The questions that were used in the interviews involved the following areas:

(1) The formation of complex ions

(2) Variable oxidation states of the transition metals

(3) Ionisation energy of transition metals

(4) Formation of coloured compounds by transition metal ions

(5) Uses of transition metals

\section{Formation of Complex Ions}

Based on the quantitative analysis of the results of the conceptual test, $50 \%$ of the students from the comparison group and $2 \%$ of the students from the treatment group held the alternative conception that a transition metal in zero oxidation state cannot attract ligands and hence cannot form complexes. The alternative conception had decreased from the comparison group to the treatment group. Students understood better after demonstrating the formation of complex ions using ICT technology rather than traditional teaching. Students could observe that transition metals have empty orbitals that can be filled by the electrons from the ligands even without donating any of the electrons.

The interview responses below show students' understanding of transition metals having zero oxidation state before the instruction took place.

Student 1: $\quad$ Transition metals have various oxidation states and it is one of their special properties.

Student 2: $\quad$ They should have more than one oxidation state like $\mathrm{Cu}$ has +1 and +2 oxidation states.

Student 3: $\quad$ Transition metals can donate more than one electron to form various oxidation states.

Student 4: $\quad$ All metals have oxidation states.

Student 5: Don't know.........Maybe they can because if it is a solid then it will have zero oxidation state.

Based on students' responses, it may be concluded that all the five students had some level of alternative conceptions about the formation of zero oxidation state by transition metals. Student 5 was unable to relate the oxidation number to a solid or ion. Students 1, 2, 3 and 4 basically knew that transition metals form various oxidation states.

After ICT-based instruction, the same students were interviewed using the same.

Student 1: $\quad$ Transition metals such as $\mathrm{Ni}(\mathrm{CO})_{4}$ can have zero oxidation state. Transition metals have various oxidation states including zero oxidation state.

Student 2: $\quad$ Transition metals can form complex ions with zero oxidation state.

Student 3: $\quad \mathrm{Ni}(\mathrm{CO})_{4}$ has zero oxidation state in its compound.

Student 4: $\quad$ Transition metals can have zero oxidation state. For example, nickel in $\mathrm{Ni}(\mathrm{CO})_{4}$ has zero oxidation state.

Student 5: $\quad$ Zero oxidation state can occur in transition metal compounds. 
Based on the students' answers, it may be concluded that all the students had already overcome the alternative conception on variable oxidation state in transition metals. All the students agreed that transition metals can form zero oxidation state. Students 1,3 , and 4 could include the example of $\mathrm{Ni}(\mathrm{CO})_{4}$ as having a transition metal with zero oxidation state.

\section{Variable Oxidation States}

There were three alternative conceptions that were identified about the variable oxidation states of transition metals. As many as $59 \%$ of the students from the comparison group and $6 \%$ of the students from the treatment group believed that the tendency for transition metals to involve all $3 d$ electrons in bonding will not decrease once the $d^{5}$ configuration is exceeded. When the $\mathrm{d}^{5}$ configuration is exceeded, the electrons will start to pair up and there will be less tendency to involve electrons from the $\mathrm{d}$ orbitals to form bonds. The CD provided by the Ministry of education helped students to understand that when the $\mathrm{d}$ orbital is half-filled, the electrons will start to pair up and will reduce the formation of bonds.

Interview responses below show that before the ICT-based instruction, the involvement of the electrons in bonding in transition metals decreases once the $\mathrm{d}^{5}$ configuration is exceeded.

Student 1: $\quad$ Metals form ionic bonds. Hmmm...I don't think so because transition metals need to donate higher number of electrons to form ionic bonds.

Student 2: $\quad$ No, because transition metals have many empty orbitals. They can fill the empty orbitals such as $4 s, 4 p$ and $4 d$ orbitals to form bonds.

Student 3: Hmmm....Transition metals with higher number of electrons cannot form bonds with the ligands because higher energy is needed to donate all the electrons.

Student 4: $\quad$ To donate more electrons, more energy is needed.

Student 5: $\quad H m m . . . n o t$ sure... but I think transition metals are reactive because they are catalysts for most reactions. So they can form more bonds.

It may be concluded that students are not very sure about bond formation after the $\mathrm{d}^{5}$ configuration is exceeded. Students 1, 3 and 4 held the alternative conception that transition metals can only form ionic bonds. Student 2 held the alternative conception that the electrons can be expanded to $4 \mathrm{~s}, 4 \mathrm{p}$ and $4 \mathrm{~d}$ orbitals. Student 5 held the alternative conception that the transition metals are reactive.

The interview responses below show the students' understanding after ICT-based instruction was carried out.

Student 1: Yes, it decreases because after the $d^{5}$ configuration has exceeded, the electrons will start to pair up and will not be available for bonding.

Student 2: $\quad$ It decreases because electrons will pair up after the $d^{5}$ configuration has been exceeded.

Student 3: $\quad$ Once the electrons pair up in each orbital, they will not be available for bonding.

Student 4: $\quad$ Involvement of the electrons for bonding in transition metals decreases because the number of unpaired electrons also decreases after the $d^{5}$ configuration is exceeded.

Student 5: $\quad$ Involvement of the electrons for bonding in transition metals decreases because electrons will pair up in each d orbital.

Based on the students' answers it may be concluded that most of them had overcome the alternative conception. All of them knew that the tendency for transition metals to involve all $3 \mathrm{~d}$ electrons in bonding will decrease once the $\mathrm{d}^{5}$ configuration is exceeded because the electrons will pair up and will not be available for bonding.

\section{Reactivity of Transition Metals}

Another alternative conception held by students was that the reactivity of transition metals increases from left to right across a period. Reactivity of the transition metals decreases as there is a decrease to involve the electrons from the $\mathrm{d}$ orbitals to form bonds. Fifty percent of students from the comparison group held this alternative conception but only $9 \%$ of the students held this alternative conception in the treatment group, showing a decrease in the alternative conception held by the students in the treatment group compared to comparison group.

\section{Transition Metals as Reducing Agents}

A total of $63 \%$ of students from the comparison group believed that transition metals are not good reducing agents. However, this alternative conception had decreased to $4 \%$ of the students in the treatment group. 


\section{Ionisation Energy of Transition Metals}

Students held the alternative conception about the ionisation energy of transition metals compared to the ionisation energy of s-block metals with $53 \%$ of the students from the comparison group holding the alternative conception that the ionisation energy of transition metals down a group in the Periodic Table is similar to that of the alkali metals. Only $4 \%$ from the treatment group believed similarly.

Also, $63 \%$ of students from the comparison group held the alternative conception that $\mathrm{Cu}$ and $\mathrm{K}$ are expected to have the same ionisation energy for the loss of their 4 s electrons while only $9 \%$ of the treatment group students held this alternative conception. This alternative conception arose due to the poor understanding of the students about the trend in the ionisation energy of transition metals and s-block metals.

Result from the interview before instruction about whether copper and potassium have the same ionization energy:

Student 1: $\quad h m m . . . I$ don't think so.

Student 2: $\quad$ They have the same ionisation energy.

Student 3: No...

Student 4: Hmmm...not the same I think.

Student 5: $\quad$ Can be the same...

Responses of students that copper and potassium have same or different ionization energy are given below:

Student 1: $\quad$ Because they are different elements with different electronic configurations, different amount of energy is needed to remove the electron.

Student 2: $\quad$ Because potassium and copper are in the same row in the Periodic Table. So they can have the same ionisation energy.

Student 3: $\quad$ Potassium is a group 1 metal and copper is a transition metal. So the ionisation energy must be different.

Student 4: $\quad$ Both are metals and can donate electrons easily. Therefore, their ionisation energy can be the same with the same oxidation number.

Student 5: $\quad$ Because both are metals and both can form $\mathrm{Cu}^{+}$and $\mathrm{K}^{+}$, both involve the removal of one electron.

Based on the students' answers it may be concluded that most of the students (Student 2, 3, and 4) held alternative conceptions. Student 2 held the alternative conception that if metals are in the same row they have the same ionisation energy. Student 4 held the alternative conception that metals can donate electrons, therefore, they have the same ionisation energy. Student 5 held the alternative conception that if the oxidation number is the same, the metals are most likely to have the same ionisation energy. Students understood the term ionisation energy but they could no explain the trend of the ionisation energy. Students 1 and 3 believed that they were different metals and so they have different ionisation energies.

Responses from interviews after ICT-based instruction are as follows:

Student 1: $\quad$ The ionisation energy of potassium is lower than that of copper. The first electron is being removed from the 4 s orbital of copper and potassium. The size of the copper atom is smaller than that of the potassium atom. The nuclear charge of copper is also higher than that of potassium. In conclusion, the 4s electron in copper is more strongly held by the nucleus and so is more difficult to be removed.

Student 2: $\quad$ The ionisation energy of potassium is lower than that of copper because the atomic size of potassium is larger than that of copper. Therefore, the valence electrons in copper are more strongly held by the nucleus compared to potassium. More energy is need to remove the valence electron in copper compared to potassium.

Student 3: $\quad$ : It doesn't have the same ionisation energy. Potassium has a larger size than copper. Potassium has lower nuclear charge than copper. Thus, the ionisation energy for potassium is lower than copper.

Student 4: $\quad$ Potassium with larger size and lower nuclear charge would be expected to have lower ionisation energy than copper. Less energy is needed to remove an electron from potassium compared to copper.

Student 5: $\quad$ Copper and potassium don't have the same ionisation energy. This is because the energy needed to remove an electron from copper is higher than potassium. Copper has a smaller atomic size than potassium and larger proton number than potassium. More energy is needed to remove an electron from copper compared to potassium because the outermost electron in copper has stronger attraction towards the nucleus compared to potassium. So the ionisation energy in copper is higher than potassium

It may be concluded that all the students had overcome the alternative conceptions only up to a certain extent after instruction. Only students 1 and 5 had a complete idea by comparing the ionisation energy between a transition metal and an alkaline earth metal. These students compared the size, nuclear charge, strength of nucleus 
holding the outermost electron and energy needed to remove the electron. Students 2, 3 and 4 gave brief responses comparing the size and nuclear charge only to describe the ionisation energy.

\section{Formation of Colours in Transition Metal Ions}

ICT-based instruction plays an important role in reducing the alternative conception about the formation of coloured ions of transition metals. The teacher showed the experimental group students the video of $d$ orbitals that can be split into two energy levels and the promotion of the electrons from a lower energy level to a higher energy level. Students also managed to see all the shapes of the d orbitals in the video presented as it is difficult to draw on the board. Thus, students were able to visualize the shapes of the $\mathrm{d}$ orbitals and the reason transition metal ions are coloured. As a result, only $11 \%$ of the students from the treatment group held the alternative conception that $\mathrm{Cu}^{+}$has unpaired d electrons which can take part in $d$-d transitions. In the traditional teaching method, students could not visualize $\mathrm{d}$ orbitals well because the teacher showed the shapes of the d orbitals from the textbook. This resulted in $53 \%$ of students from the comparison group holding an alternative conception. Another prevalent alternative conception among students was that not only transition metal ions are coloured. Students perceived that there are other coloured ions as well. Students from the treatment group understood that any metals that undergo d-d transition are coloured whereas students from the traditional teaching failed to understand this.

The teacher questioned the students to find out why the $\mathrm{Cu}^{+}$ion is colourless.

Student 1: $\quad H m m . .$. don't know.

Student 2: $\quad$ No idea.

Student 3: $\quad$ Not sure.

Student 4: $\quad$ All transition metals ions are coloured except for $\mathrm{Cu}^{+} . . . h m m$.

Student 5: Don't know.

Based on the students' answers, it may be concluded that all the students have alternative conceptions about the formation of the colour of the $\mathrm{Cu}^{+}$ion. None of them gave a correct response. Students were not sure of the reason why the $\mathrm{Cu}^{+}$ion is colourless because they assumed that all transition metal ions are coloured.

After ICT-based instruction, students showed positive results in their interview responses.

Student 1: $\quad$ Because the copper ion has fully filled d orbitals. Thus, $\mathrm{Cu}^{+}$cannot undergo d-d transition.

Student 2: $\quad C u^{+}$cannot undergo d-d transition. There will be no electrons promoted to a higher energy level to absorb a certain amount of wavelength to reflect the colours. That's why it is colourless.

Student 3: $\quad \mathrm{C} u^{+}$has fully filled $d$ orbitals and there will be no electrons promoted to a higher energy level. There is no $d-d$ transition and hence $\mathrm{Cu}^{+}$is not coloured.

Student 4: $\quad d$ orbitals are fully filled. Any metals that undergo d-d transition are coloured. All transition metals ions are coloured except for $\mathrm{Cu}^{+}$. So, $\mathrm{Cu}^{+}$cannot undergo d-d transition because electrons are not being promoted to higher energy level.

Student 5: $\quad d$ orbitals of $\mathrm{Cu}^{+}$are fully filled. None of the electrons from the $\mathrm{Cu}^{+}$get promoted to a higher energy level. So, it is colourless.

It may be concluded that all the students held alternative conceptions before instruction on the formation of the colour. None of them gave a correct response. Students were not sure of the reason why the $\mathrm{Cu}^{+}$ion is colourless because they have a conception that all transition metal ions are coloured.

\section{Uses of Transition Metals}

One alternative conception that students held was that transition metals are not good catalysts. Forty-four percent of the students from the comparison group misunderstood that transition metals are not good catalysts whereas only $9 \%$ of the students from the treatment group managed to comprehend the correct concept. After the treatment it was found that students from the treatment group understood that transition metals have empty $\mathrm{d}$ orbitals that could be occupied by the electrons to form temporary bonds. Thus, they can be good catalysts compared to the other metals. The teacher in the ICT-based instruction helped to improve students' understanding by showing all empty orbitals that existed in transition metals with examples. 
Table 4. The percentage of students' having alternative conception as determined in the conceptual test after instruction

\begin{tabular}{|c|c|c|c|}
\hline $\begin{array}{l}\text { Items } \\
\text { nos. }\end{array}$ & Alternative conceptions & $\begin{array}{c}\text { Comparison } \\
\text { group (\%) }\end{array}$ & $\begin{array}{l}\text { Treatment } \\
\text { group (\%) }\end{array}$ \\
\hline 1 & $\begin{array}{l}\text { A transition metal in zero oxidation state cannot attract ligands and hence cannot form } \\
\text { complexes. }\end{array}$ & 50 & 2 \\
\hline 2 & $\begin{array}{l}\text { The tendency for transition metals to involve all } 3 d \text { electrons in bonding will not decrease once } \\
\text { the } d^{5} \text { configuration is exceeded. }\end{array}$ & 59 & 6 \\
\hline 3 & $\mathrm{Cu}^{+}$has unpaired $\mathrm{d}$ electrons that can take part in $\mathrm{d}-\mathrm{d}$ transitions. & 53 & 11 \\
\hline 4 & $\mathrm{Cu}$ and $\mathrm{K}$ are expected to have the same ionisation energy for the loss of their $4 \mathrm{~s}$ electrons. & 63 & 9 \\
\hline 5 & The reactivity of transition metals increases from left to right across a period. & 50 & 9 \\
\hline 6 & $\begin{array}{l}\text { The ionisation energy of transition metals down a group in the Periodic Table is similar to that } \\
\text { of the alkali metals. }\end{array}$ & 53 & 4 \\
\hline 7 & Not only transition metal ions are coloured. & 72 & 6 \\
\hline 8 & Transition metals are not good reducing agents. & 63 & 4 \\
\hline 9 & Transition metals are not good catalysts. & 44 & 9 \\
\hline
\end{tabular}

Based on the post-instruction interviews, students' understanding about transition metals improved after the intervention. Students from the comparison group understood the transition metals concepts better than before. Students displayed alternative conceptions in the formation of complex ions, variable oxidation states of the transition metals, ionisation energy of transition metals, formation of the colours in transition metal ions and the uses of transition metals before instruction. However, after the intervention, the incidence of alternative conceptions had been reduced.

\section{CONCLUSION}

This study used a two-tier questionnaire about transition metals to ascertain the alternative conceptions that existed among form six students. The treatment group used ICT-based instruction to teach the students about transition metals whereas traditional teaching was used with the comparison group. In response to the research question of the study (What is the effect of ICT-based instruction on reducing the incidence of alternative conceptions about the chemistry of transition metals among Form 6 students?), this study showed that ICT-based education improved students understanding compared to the traditional teaching method. In addition, students were interviewed before and after the treatment to see if ICT-based instruction had improved their understanding about transition metals. It was found ICT-based instruction helped the students to reduce the incidence of alternative conceptions and improved their understanding about transition metals. Tsai and Chou (2002) in their research found that the achievement of the students increased with the use of computers in science education. Similarly, Kim et.al. (2013) described ICT as having an important role in improving teaching and learning. This study will contribute to the improvement of chemistry teaching especially about transition metals. Teachers' awareness of students' understanding before a lesson is very important to help reduce alternative conceptions, indirectly contributing to the improvement of teaching and achievement of better understanding in a particular topic.

\section{REFERENCES}

Adam, T., \& Tatnall, A. (2010). Use of ICT to assist students with learning difficulties: An actor-network analysis. In N. Reynolds \& M. Turcsanyi-Szabo (Eds.), Key competencies in the knowledge society (pp. 1-11). New York, NY: Springer. https:/ / doi.org/10.1007/978-3-642-15378-5_1

Agung, S., \& Schwartz, M. S. (2007). Students' understanding of conservation of matter, stoichiometry and balancing equations in Indonesia. International Journal of Science Education 29(3), 1679-702. https:/ / doi.org/10.1080/09500690601089927

Anderson, J. (2002). Being mathematically educated in the twenty-first century: What should it mean? In L. Haggarty (Ed.), Teaching Mathematics in Secondary Schools, London, UK: Routledge Falmer. https:/ / doi.org/10.4324/9781315013152

Anderson, R. (2008). Implications of the information and knowledge society for education. In J. Voogt, \& G. Knezek (Eds.), International handbook of information technology in primary and secondary education. New York, NY: Springer. https:/ / doi.org/10.1007/978-0-387-73315-9_1

Artdej, R., Ratanaroutai, T., \& Coll, R. K. (2010). Thai grade 11 students' alternative conceptions for acid-base chemistry. Research in Science $\mathcal{E}$ Technological Education, 28(2), 167-183. https://doi.org/10.1080/02635141003748382 
Ausubel, D. (1968). Educational Psychology: A Cognitive View. Holt, Rinehart and Winston, New York. https://doi.org/10.3102/00028312005003421

Barak, M. (2017). Science teacher education in the twenty-first century: a pedagogical framework for technologyintegrated social constructivism. Research in Science Education, 47(2), 283-303. https:/ / doi.org/10.1007/s11165-015-9501-y

Bayraktar, Ş. (2000). A meta-analysis on the effectiveness of computer-assisted instruction in science education (Unpublished Master Dissertation), Ohio University, US. https:/ / doi.org/10.1080/15391523.2001.10782344

Coll, R. K., \& Treagust, D. F. (2003). Learners' mental models of metallic bonding: A cross-age study. Science Education 87(5), 685-707. https:/ / doi.org/10.1002/sce.10059

Drechsle, M., \& Schmidt, H-J. (2005). Textbooks' and teachers' understanding of acid-base models used in chemistry teaching. Chemistry Education Research and Practice 6(1), 19-35. https:/ / doi.org/10.1039/B4RP90002B

Furió-Más, C., Calatayud, M. L., \& Bárcenas, S. L. (2007). Surveying students' conceptual and procedural knowledge of acid-base behavior of substances. Journal of Chemical Education 84(10), 1717-24. https://doi.org/10.1021/ed084p1717

Goedhart, M. J., \& Kaper, W. (2002). From chemical energetics to chemical thermodynamics. In Gilbert, J. K., Jong, O. D., Justi, R., Treagust, D. F., and Van Driel, J. H. (Eds), Chemical Education: Towards Research-Based Practice. Kluwer, Dordrecht, The Netherlands, pp.339-362. https://doi.org/10.1007/0-306-47977-x_15

Goktas, Y., \& Yildrim, Z. (2003). A comparative analysis of the EU countries' and Turkey's regarding the integration of ICT in primary education curricula and teacher education programs, Retrieved from http:/ / www.leeds.ac.uk/educol/documents/00003490.htm

Gyöngyösi, E. (2005). Continuing education for mathematics teachers of secondary education to use computers more effectively and to improve education. Retrieved from http:/ / www.cimt.plymouth.ac.uk/journal/egcomp.pdf.

Hadfield, L. C., \& Wieman C. E. (2010). Student interpretations of equations related to the first law of thermodynamics. Journal of Chemical Education 87(7), 750-755. https:/ / doi.org/10.1021/ed1001625

Hu, X., Gong, Y., Lai, C., \& Leung, F. K. (2018). The relationship between ICT and student literacy in mathematics, reading, and science across 44 countries: A multilevel analysis. Computers $\mathcal{E}$ Education. https:// doi.org/10.1016/j.compedu.2018.05.021

Johnstone, A. D. (1971). The spreading of a proton beam by the atmosphere. Planetary and Space Science, 20(2), 292295. https:/ / doi.org/10.1016/0032-0633(72)90111-0

Johnstone, A. H. (1991). Why is science difficult to learn? Things are seldom what they seem. Journal of Computer Assisted Learning 7(2), 75-83. https:/ / doi.org/10.1111/j.1365-2729.1991.tb00230.x

Kao, H. L. (2007). A Study of Aboriginal and Urban Junior High School Students' Alternative Conceptions on the Definition of Respiration. International Journal of Science Education, 29(4), 517-533 https:/ / doi.org/10.1080/09500690601073376

Kim, C., Kim, M. K., Lee, C., Spector, J. M., \& DeMeester, K. (2013). Teacher beliefs and technology integration. Teaching and Teacher Education, 29, 76-85. https:/ / doi.org/10.1016/j.tate.2012.08.005

Lai, C. L., Hwang, G. J., \& Tu, Y. H. (2018). The effects of computer-supported self-regulation in science inquiry on learning outcomes, learning processes, and self-efficacy. Educational Technology Research and Development, 130. https:/ / doi.org/10.1007/s11423-018-9585-y

McClary, L. M., \& Bretz, S. L. (2012). Development and assessment of a diagnostic tool to identify organic chemistry students' alternative conceptions related to acid strength. International Journal of Science Education, 34(5), 2317-2341. https:// doi.org/10.1080/09500693.2012.684433

Mulford, D. R., \& Robinson, W. R. (2002). An inventory for alternate conceptions among first semester general chemistry students. Journal of Chemical Education 79(6), 739-744. https:/ / doi.org/10.1021/ed079p739

Nieswandt, M. (2001). Problems and possibilities for learning in an introductory chemistry course from a conceptual change perspective. Science Education, 85(2), 158-179. https://doi.org/10.1002/1098237X(200103)85:2<158::AID-SCE40>3.0.CO;2-3

Özmen, H. (2004). Some Student Misconceptions in Chemistry: A Literature Review of Chemical Bonding. Journal of Science Education and Technology, 13(2), 147-159. https:/ / doi.org/10.1023/ B:JOST.0000031255.92943.6d

Smith K. C., \& Nakhleh M. B. (2011). University students' conceptions of bonding and melting and dissolving phenomena. Chemistry Education Research and Practice, 12(4), 398-408. https:/ / doi.org/10.1039/C1RP90048J 
Sözbilir, M., Pinarbasi, T., \& Canpolat, N. (2010). Prospective chemistry teachers' conceptions of chemical thermodynamics and kinetics. Eurasia Journal of Mathematics, Science E Technology Education, 6(2), 111-120. https://doi.org/10.12973/ejmste/75232

Sreenivasulu, B., \& Subramaniam, R. (2014). Exploring undergraduates' understanding of transition metals chemistry with the use of cognitive and confidence measures. Research in Science Education, 44(6), 801-828. https://doi.org/10.1007/s11165-014-9400-7

Taber, K. S., \& Coll, R. K. (2002). Bonding. In Gilbert, O. De Jong, R. Justi, D. F. Treagust \&J.H. Van Driel (Eds.), Chemical Education: Towards Research-Based Practice, pp. 213-234. Dordrecht, The Netherlands: Kluwer. https:/ / doi.org/10.1007/0-306-47977-x_10

Treagust, D. F. (1988). Development and use of diagnostic tests to evaluate students' misconceptions in science. International Journal of Science Education 10(2), 159-169. https:/ / doi.org/10.1080/0950069880100204

Tsai, C.-C. (2000). Enhancing science instruction: The use of conflict maps. International Journal of Science Education 22(3), 285-302. https:/ / doi.org/10.1080/095006900289886

Tsai, C.-C., \& Chou, C. (2002). Diagnosing students' alternative conceptions in science. Journal of Computer Assisted Learning, 18(2), 157-165. https:/ / doi.org/10.1046/j.0266-4909.2002.00223.x

Yushau, B., Mji, A., \& Wessels, D. C. J. (2003). Creativity and computer in the teaching and learning of mathematics. Retrieved from www.kfupm.edu.sa/math/UPLOAD/Tech_Reports/311.pdf

\section{http://www.ejmste.com}

